\title{
SPEED CONTROL OF SEPARATELY EXCITED DC MOTOR USING FUZZY NEURAL MODEL REFERENCE CONTROLLER
}

\author{
Waleed I. Hameed ${ }^{1}$ and Khearia A. Mohamad ${ }^{2}$ \\ ${ }^{1}$ Department of Electrical Engineering, University of Basrah, Basrah, IRAQ \\ waleed_ishaq5 dyahoo.com \\ ${ }^{2}$ Department of Electrical Engineering, University of Basrah, Basrah, IRAQ \\ khearia_ibrahimy@yahoo.com
}

\begin{abstract}
Conventional controllers are generally used to control the speed of the separately excited DC motors in various industrial applications. It is found to be simple and high effective if the load disturbances is small. So the drawback of Conventional controllers when high load has been applied to the DC motor. This paper presents the speed control of a separately excited dc motor using Fuzzy Neural Model Referance controller. The system has been implemented using Matlab/Simulink software. The simulation results show that presenting controller give good performance and high robustness in load disturbance.
\end{abstract}

\section{KEYWORDS}

Separately excited DC motor, Chopper circuit, Hysteresis current control, Speed control, Model reference adaptive controller, Fuzzy neural controller.

\section{INTRODUCTION}

The speed of DC motors can be adjusted within wide boundaries so that this provides easy controllability and high performance. DC motors used in many applications such as steel rolling mills, electric trains, electric vehicles, electric cranes and robotic manipulators require speed controllers toper form their tasks[1]. The most flexible control is obtained by means of separately excited DC Motor in which the armature and field circuits are provided with separate sources. For the armature source a controlled rectifier or chopper is required[2]. Armature voltage control method is used to vary the speed up to the rated speed and the motor operates in the constant torque region[3]. Conventional controllers such as PI and PID have been applied to control the speed of DC motors. The disadvantages of using conventional controllers are that they are sensitive to variation in the motor parameters and load disturbance. In addition, it is difficult to tune PI or PID gains to eliminate and reduce the overshoot and load disturbance. In order to avoid the shortcomings of conventional controllers, researchers applied adaptive control techniques for DC motor speed control to achieve parameter insensitivity and fast speed response[4]. Model reference adaptive controller (MRAC), was originally proposed to solve a problem in which the specifications are given in terms of a reference model that tells how the process output ideally should respond to the command signal[5]. In particular, the possible use of fuzzy systems in modeling and control has generated great attention. Unfortunately, it is difficult for systems designers to obtain optimal fuzzy rules because these are most likely to be influenced by the 
intuitiveness of the operators and systems designers. Neural network implementation of fuzzy systems has been proposed as possible approach for fuzzy systems design. In resulting systems, which are sometimes called neural-network-based fuzzy systems, fuzzy-neural network or neuralfuzzy network, will possess the advantage of both types of systems ( Neural network and Fuzzy system) and overcome the difficulties of each type of system. Fuzzy-Neural is a hybrid system which functions as fuzzy system with processing mechanism realized by fuzzy-neural network[6]. Recently, the use of fuzzy and neural networks to identify and control nonlinear dynamic systems has been proposed because they can approximate a wide range of nonlinear functions to any desired degree of accuracy[7]. The objective of fuzzy neural controller is to develop a back propagation algorithm such that the output speed of the plant can track the reference command signal[8]. In this paper, Fuzzy Neural Model Reference Controller has been proposed to control the Speed of Separately Excited DC Motor. This paper is organized as follows; the model of separately excited DC motor is given in section 2, modeling of circuit drive based on chopper is given in section 3, also hysteresis current controller (HCC) is given in section 4, in section 5, the proposed method has been presented to control the speed of separately excited DC motor. Simulation results are given in section 6, and finally, conclusions are given in section 7.

\section{MODELING OF SEPARATELY EXCITED DC MOTOR}

In modeling, the aim is to find the governing differential equations that relate the applied voltage with the produced torque or speed of the rotor[9]. Figure 1 shows the equivalent circuit with armature voltage control and the model of a general mechanical system that incorporates the mechanical parameters of the motor and the mechanism coupled to it $[2,10]$.

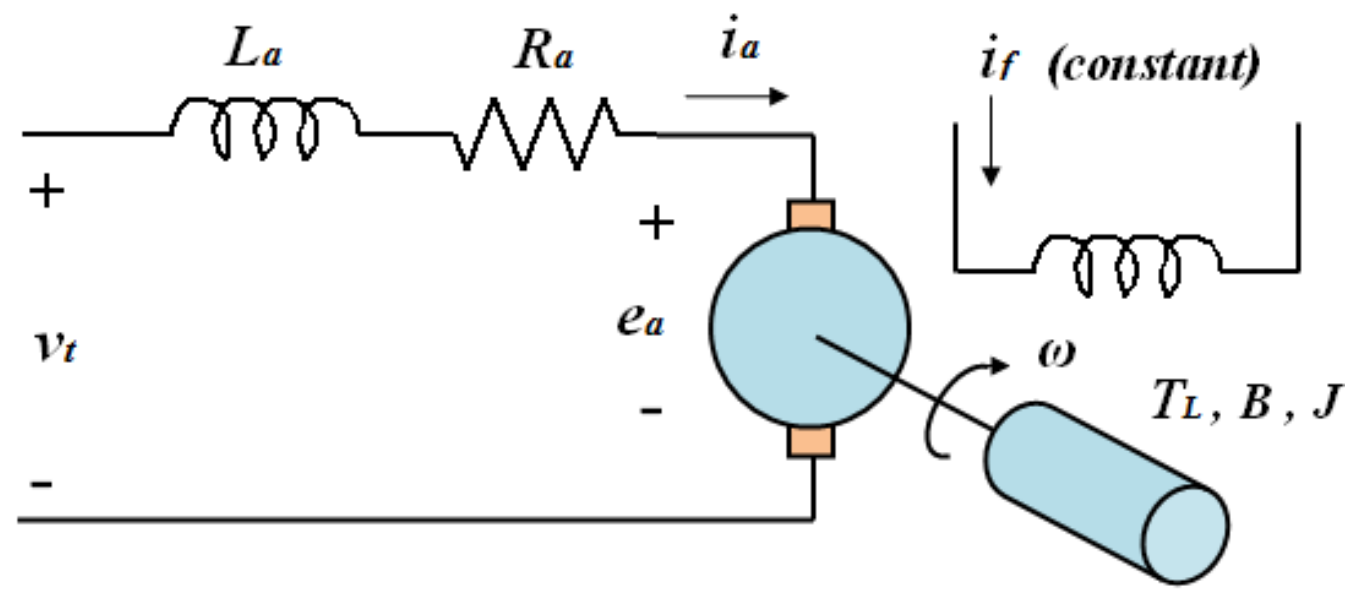

Figure 1. Equivalent circuit of a separately exited DC-Motor.

The model of the motor consists of a mechanical equation and electrical equation as determined in the following equations[1,2]:

$$
\begin{aligned}
& v_{t}=e_{\mathrm{c}}+L_{a} \frac{d i_{a}}{d t}+R_{a} i_{a} \\
& e_{a}=k \varphi \omega \\
& T_{a}=k \varphi i_{\mathrm{a}}=J \frac{d \omega}{d t}+B \omega+T_{L}
\end{aligned}
$$

where $v_{t}$ is the applied terminal voltage to the motor, $e_{a}$ is the emf induced in the armature winding, $L_{a}$ is the armature inductance of the motor, $i_{a}$ is the armature motor current, $R_{a}$ is the 
armature resistance of the motor, $k \varphi$ is the motor constant, $\omega$ is the motor speed, $T_{q}$ is the internal torque of the motor, $J$ is the rotational inertia of motor, $B$ is the viscous friction of motor and $T_{L}$ the load torque.

Table 1 presents the separately excited DC motor characteristics.

Table 1. DC motor parameters

\begin{tabular}{|l|c|}
\hline Rated motor speed $N$ & 500 R.P.M \\
\hline Rated terminal voltage $v_{z}$ & $230 \mathrm{~V}$ \\
\hline Armature resistance $R_{a}$ & $0.066 \Omega$ \\
\hline Armature inductance $L_{a}$ & $0.0065 \mathrm{H}$ \\
\hline The rotational inertia $/$ & $2.83 \mathrm{Kg} / \mathrm{m}^{2}$ \\
\hline The viscous friction $D$ & $0.634 \mathrm{Nm} / \mathrm{rad} / \mathrm{s}$ \\
\hline Motor constant $k \varphi$ & $4.212 \mathrm{~V} / \mathrm{rad}$ \\
\hline Rated armature current $l_{a}$ & $143 \mathrm{~A}$ \\
\hline
\end{tabular}

Mathematical model described through Eqs.( 1) to (3) is implemented using Matlab/Simulink software. The simulink model of the separately excited DC motor block is shown in Figure 2.

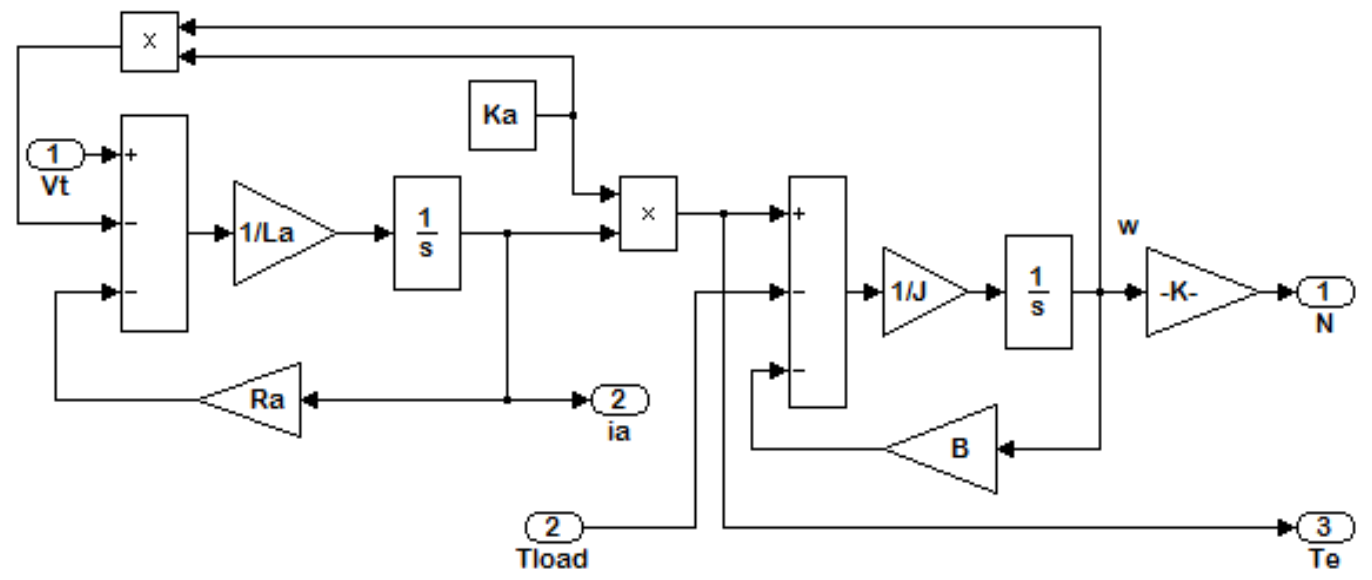

Figure 2. Simulink model of the separately excited DC motor

\section{MODELING OF DRIVE CIRCUIT}

The dc converter in the voltage step-down connection is required to convert the fixed voltage into a variable-voltage / variable-current source for the speed control of the DC motor drive. The variable DC voltage is controlled by chopping the input voltage by varying the on- and off-times of a converter, and the type of converter capable of such a function is known as a chopper $[11,12]$. A schematic diagram of the chopper is shown in Figure 3. The control voltage to it's gate is $v_{V}$. The chopper is on for a time $t_{o n}$, and it's off time is $t_{o f f}$. It's frequency of operation is

$$
f_{e}=\frac{1}{t_{\mathrm{sn}}+t_{\text {off }}}=\frac{1}{T}
$$


and it's duty cycle is defined as

$d=\frac{t_{\text {on }}}{T}$

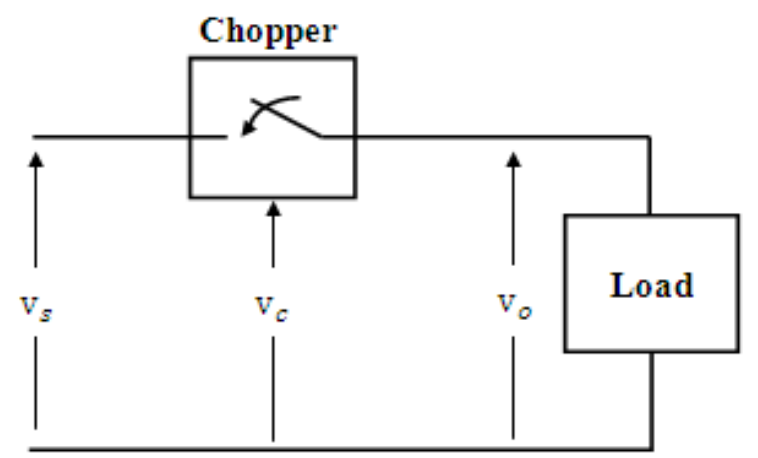

Figure 3. Chopper schematic.

Assume that the switch is ideal, with zero voltage drop, the average output voltage $v_{0}$ is given as

$v_{0}=\frac{t_{o n}}{T} v_{s}=d v_{s}$

where $v_{z}$ is the source voltage.

Varying the duty cycle changes the output voltage. Note that the output voltage follows the control voltage, as shown in Figure 4 [12].

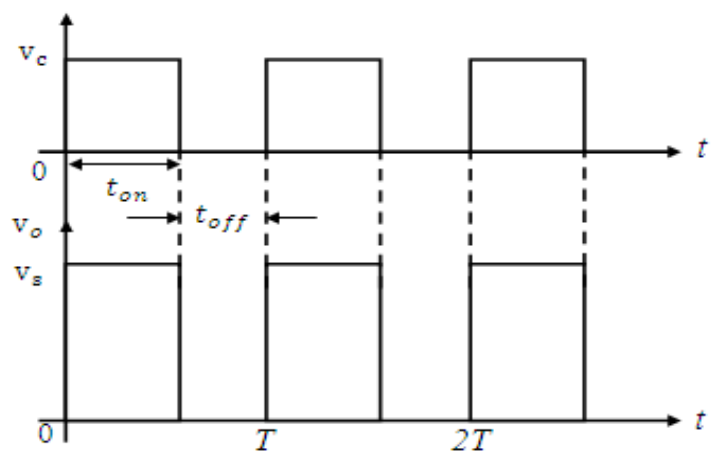

Figure 4. Voltage waveforms.

The simulink model of the chopper circuit block is shown in Figure 5.

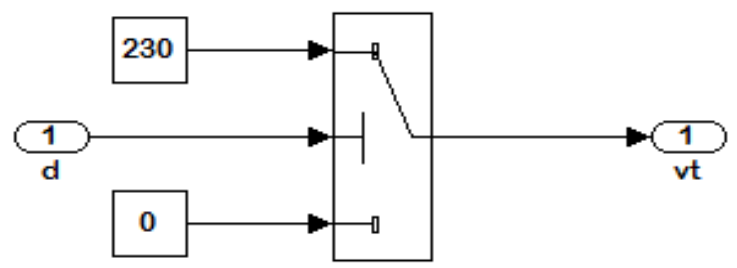

Figure 5. Simulink model of the chopper circuit 
International Journal of Instrumentation and Control Systems (IJICS) Vol.2, No.4, October 2012

\section{MODELING OF HYSTERESIS CURRENT CONTROLLER}

Current control of dc machines is very desirable because by controlling the current, the torque is controlled. Moreover, current control can be used to prevent large damaging armature currents during start-up[13]. Hysteresis current controller (HCC) is used to generate switching patterns required for the chopper circuit by comparing the actual current being drawn by the motor with the reference current[14]. In an HCC, the armature current is forced to stay within the hysteresis band determined by the upper and lower hysteresis limits $\Delta i[3]$. Commanded current and actual current are shown in Figure 6.

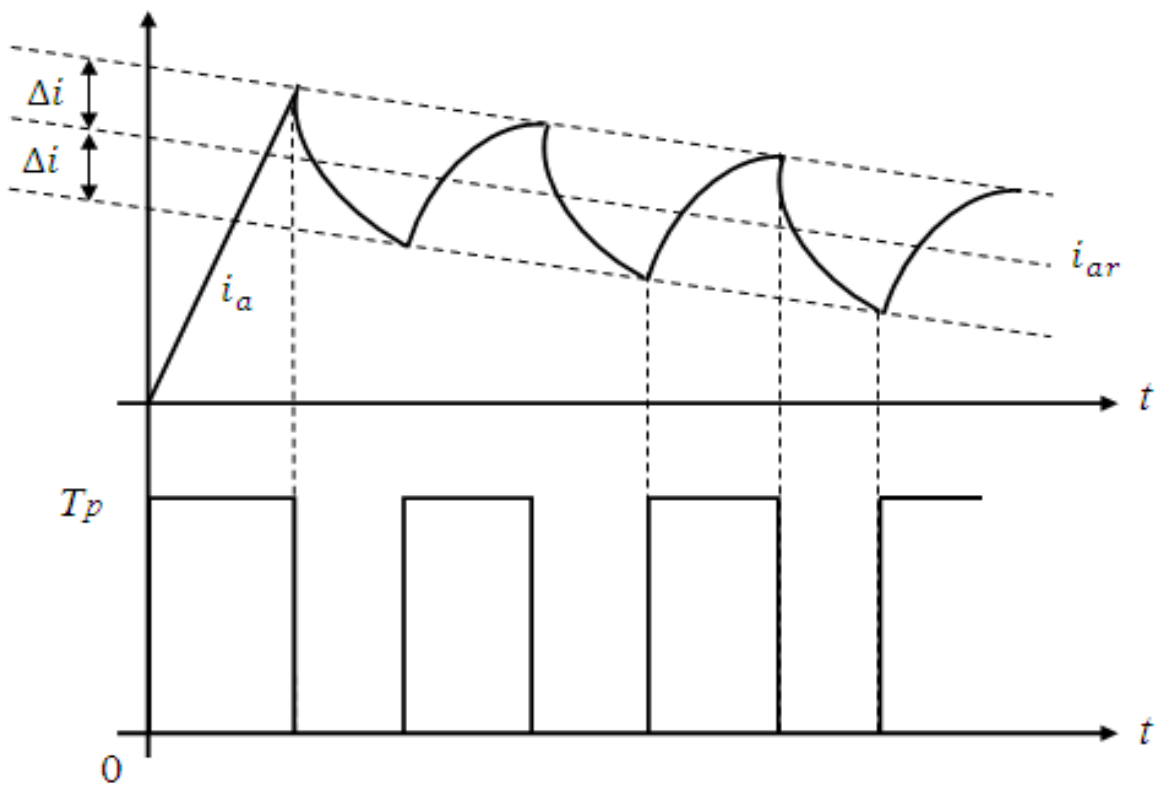

Figure 6. Hysteresis current operation.

The realization of $\mathrm{HCC}$ is shown in Figure 7. The chopping frequency is a varying quantity, unlike the constant frequency in the PWM controller[12].

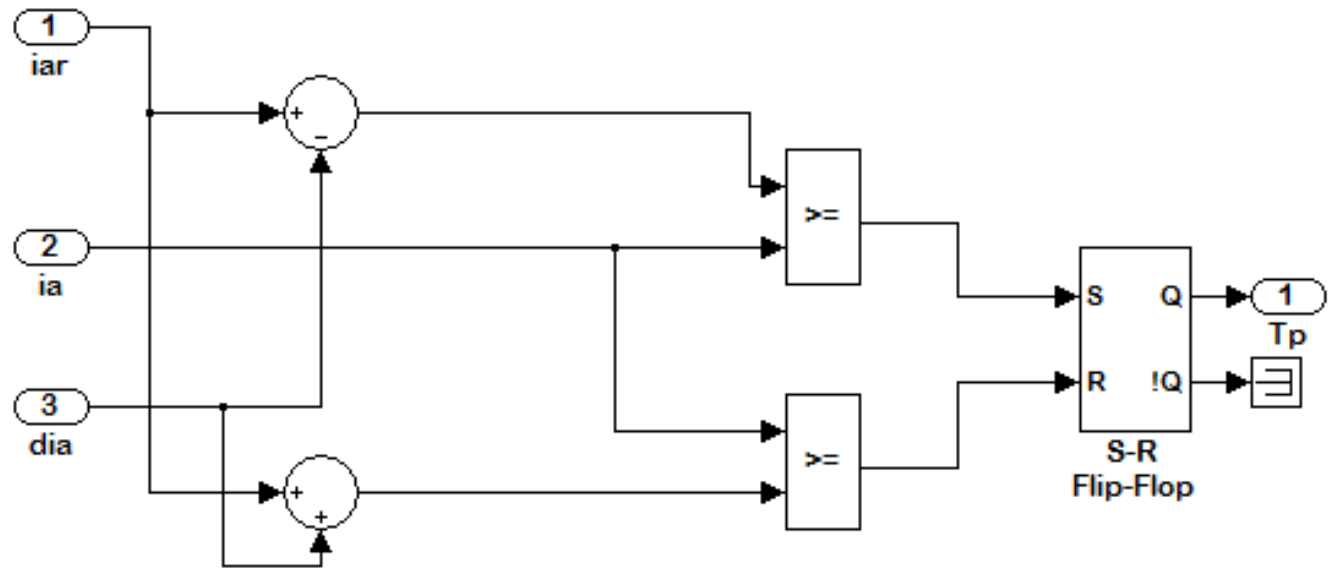

Figure 7. Simulink model of hysteresis current controller 
International Journal of Instrumentation and Control Systems (IJICS) Vol.2, No.4, October 2012

\section{FUZZY NEURAL MODEL REFERENCE CONTROLLER}

For the systems with changing parameters, the MRAC method gives a general approach for adjusting controller parameters so that the closed-loop transfer function will be close to a prescribed model[2]. Many algorithms employ a reference model to provide closed-loop performance feedback for synthesizing and tuning a fuzzy controller's knowledge-base. Consequently, these algorithms are referred to as a "Fuzzy Model Reference Learning Controller" (FMRLC). Fuzzy Neural Networks were also used instead of fuzzy systems, these algorithms denoted as "Fuzzy Neural Model Reference Controller" (FNMRC)[15]. The controller is designed such that the actual output of the process will track the desired output of the reference model. The MRAC is extensively used in neurofuzzy controllers due to its simplicity [16]. The block diagram in Figure 8 show the Speed control of Separately Excited DC Motor Using Fuzzy Neural Model Reference Controller with online tuned.

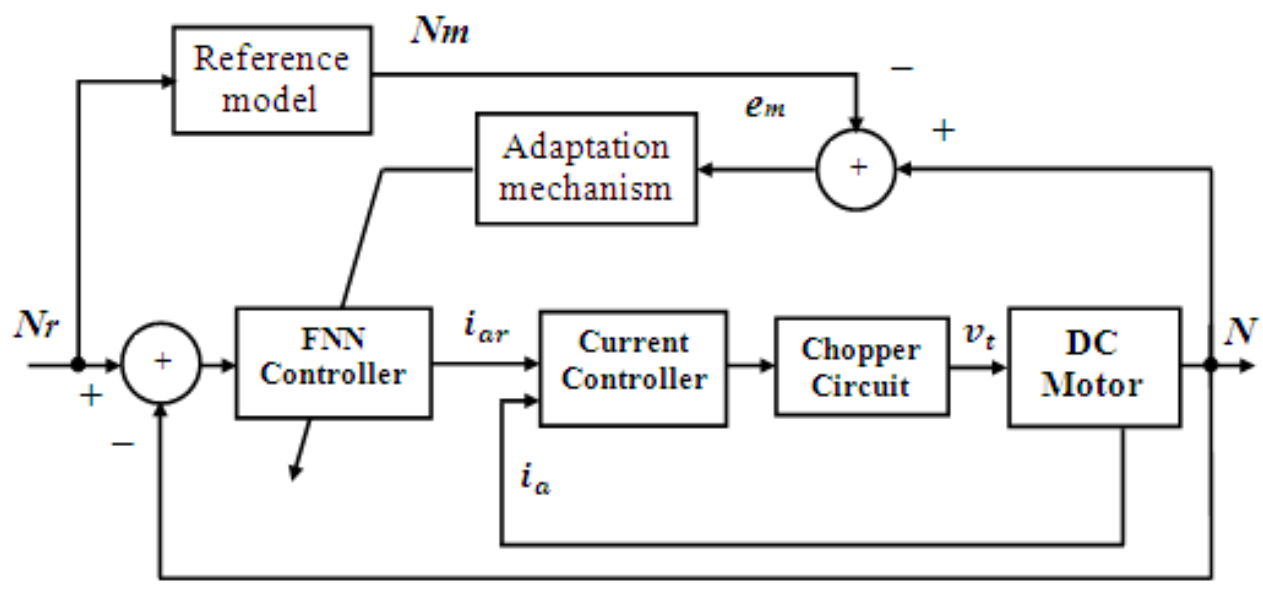

Figure 8. Block diagram of MRAC.

\subsection{Architecture of FNN}

The Architecture of FNN shown in Figure 9[17,18]. FNN considered as a special type of neural network, this means special connection and node operation. Every layer and every node have its practical meaning because the FNN has the structure which is based on both the fuzzy rules and inference[15]. In the following items each layer shown in Figure 9 will be described:

1. Input Layer I: Input layer transmits the input linguistic variables $x_{n}$ to the output without changed.

2. Hidden Layer II: Membership layer represents the input values with the following Gaussian membership functions [15]:

$\mu_{j}^{i}=\exp \left(-\frac{1}{2} \frac{\left(x_{j}-c_{i j}\right)^{2}}{s_{i j}^{2}}\right)$

Where $c_{i j}$ and $s_{i j}(\mathrm{i}=1,2, \ldots, \mathrm{n} ; \mathrm{j}=1,2, . ., \mathrm{m})$, respectively, are the mean and standard deviation of the Gaussian function in the $j^{\text {th }}$ term of the $i^{\text {th }}$ input linguistic variable $x_{2}$ to the node of this layer. 
3. Hidden Layer III: Rule layer implements the fuzzy inference mechanism, and each node in this layer multiplies the input signals and outputs the result of the product. The output of this layer is given as [15]:

$\phi_{i}=\prod_{j}^{n} \mu_{j}^{i}$

Where $\phi_{i}$ represent the $i^{\text {th }}$ output of rule layer.

4. Output Layer IV: Layer four is the output layer, and nodes in this layer represent output linguistic variables. Each node $y_{o}\left(\mathrm{o}=1, . ., N_{0}\right)$, which computes the output as:

$y_{0}=\sum_{i}^{m} w_{i} \phi_{i}$

Where $w_{i}^{0}$ represent the $i^{\text {th }}$ output weight of rule layer.

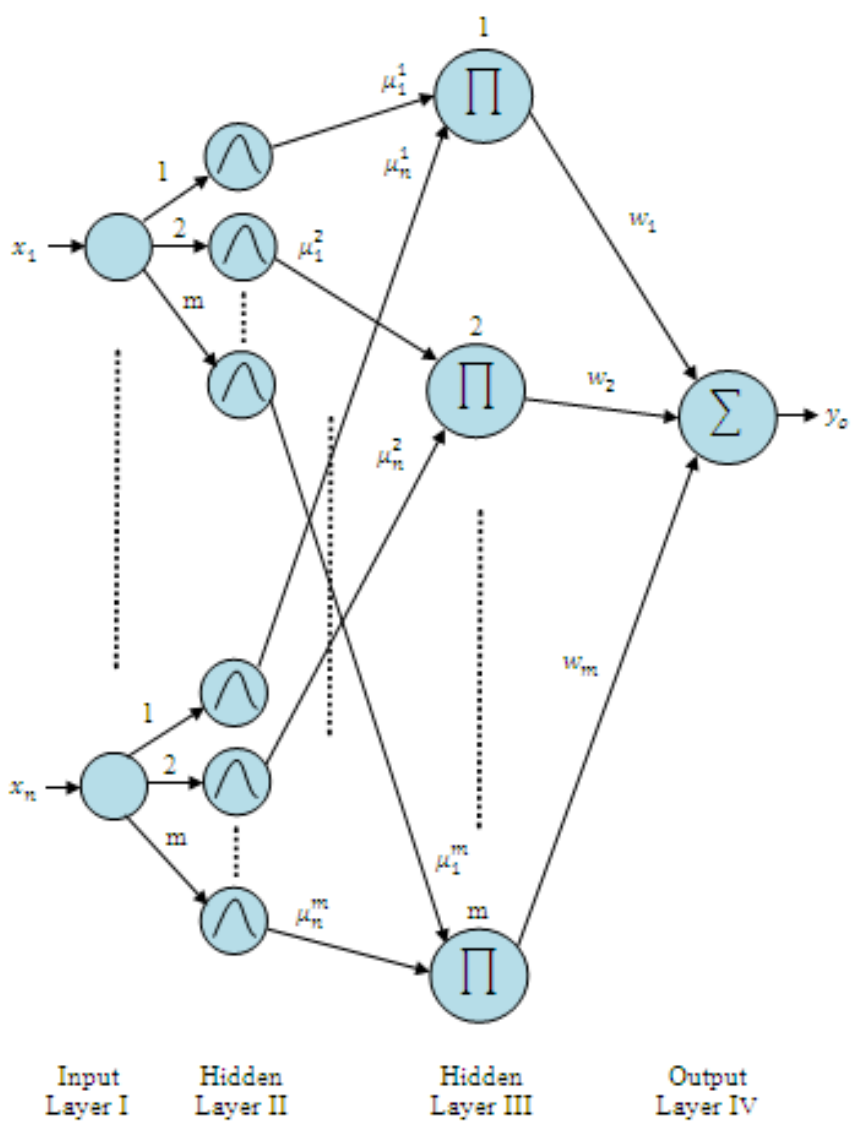

Figure 9. Architecture of FNN.

\subsection{Learning Algorithm for FNN Controller}

The parameter of the FNN controller presented in Figure 8 should be adjusted according to the following equations[19]: 


$$
\begin{aligned}
& w_{i}(k+1)=w_{i}(k)-\eta_{w} \frac{\partial E}{\partial w_{i}} \\
& c_{i j}(k+1)=c_{i j}(k)-\eta_{c} \frac{\partial E}{\partial c_{i j}} \\
& s_{i j}(k+1)=s_{i j}(k)-\eta_{s} \frac{\partial E}{\partial s_{i j}}
\end{aligned}
$$

The goal of the learning algorithm is to minimize the error between the desired output (reference model) and the motor output. In the present work the Least Mean Square (LMS) function will be used to define a criterion for the error E.

$E(k)=\frac{1}{2} e^{2}$

$e=N(k)-N_{m}(k)$

Where $\eta$ is the learning rate for each parameter in the system, $i=1,2 \ldots \mathrm{n}$ and $\mathrm{j}=1,2 \ldots \mathrm{m}$.

\section{SIMULATION RESULTS}

The SIMULINK model of Fuzzy Neural Model Reference Controller of separately excited DC motor is shown in Figure 10. The first input of the FNN is error and the second is change of error. em is the error between model reference and output of the motor that used as trajectory in adaptive mechanism. In the primes part, the number of membership functions for each input of the controller are five. So, the number of weights in the consequence part are also five. The learning rate for each parameter in the controller are shown in Table 2.

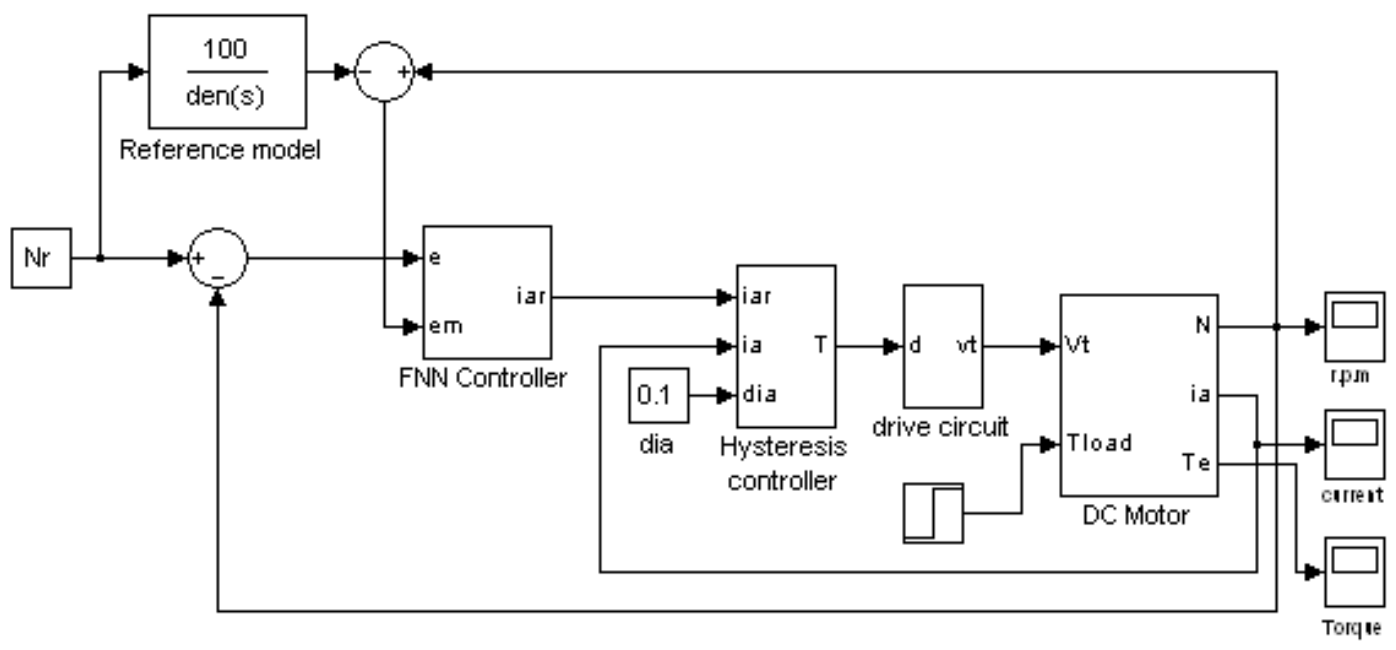

Figure 10. Simulink model of Fuzzy Neural Model Reference Controller of separately excited DC motor. 
International Journal of Instrumentation and Control Systems (IJICS) Vol.2, No.4, October 2012

Table 2. Learning rate for each parameter in the controller.

\begin{tabular}{|c|c|c|}
\hline$\eta_{w}$ & $\eta_{z}$ & $\eta_{z}$ \\
\hline 0.6 & 0.4 & 0.4 \\
\hline
\end{tabular}

With no load conditions, the rotor speed of the motor when $\mathrm{Nr}=400$ r.p.m is shown in Figure 11. Also the LMS error is shown in Figure 12. The armature current at this speed is shown in Figure 13. A step change in reference speed at $\mathrm{t}=1.25$ seconds from 400 r.p.m. to 200 r.p.m is shown in Figure 14. Figure 15. show the rotor speed of the motor when a 200 N.m load torque applied at $\mathrm{t}=1.5$ seconds. The armature current and internal torque at this speed are shown in Figure 16. and Figure 17. respectively.

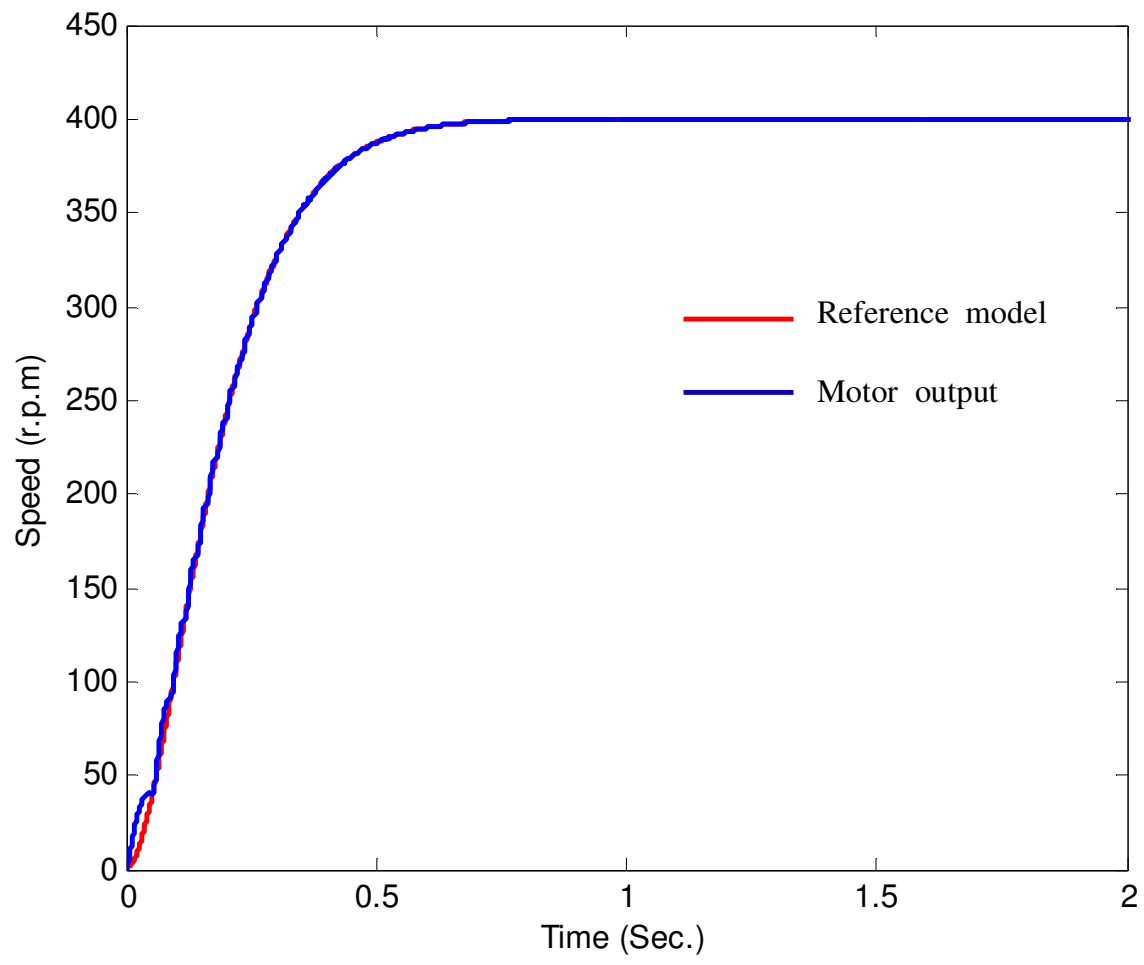

Figure 11. Rotor speed of the motor 
International Journal of Instrumentation and Control Systems (IJICS) Vol.2, No.4, October 2012

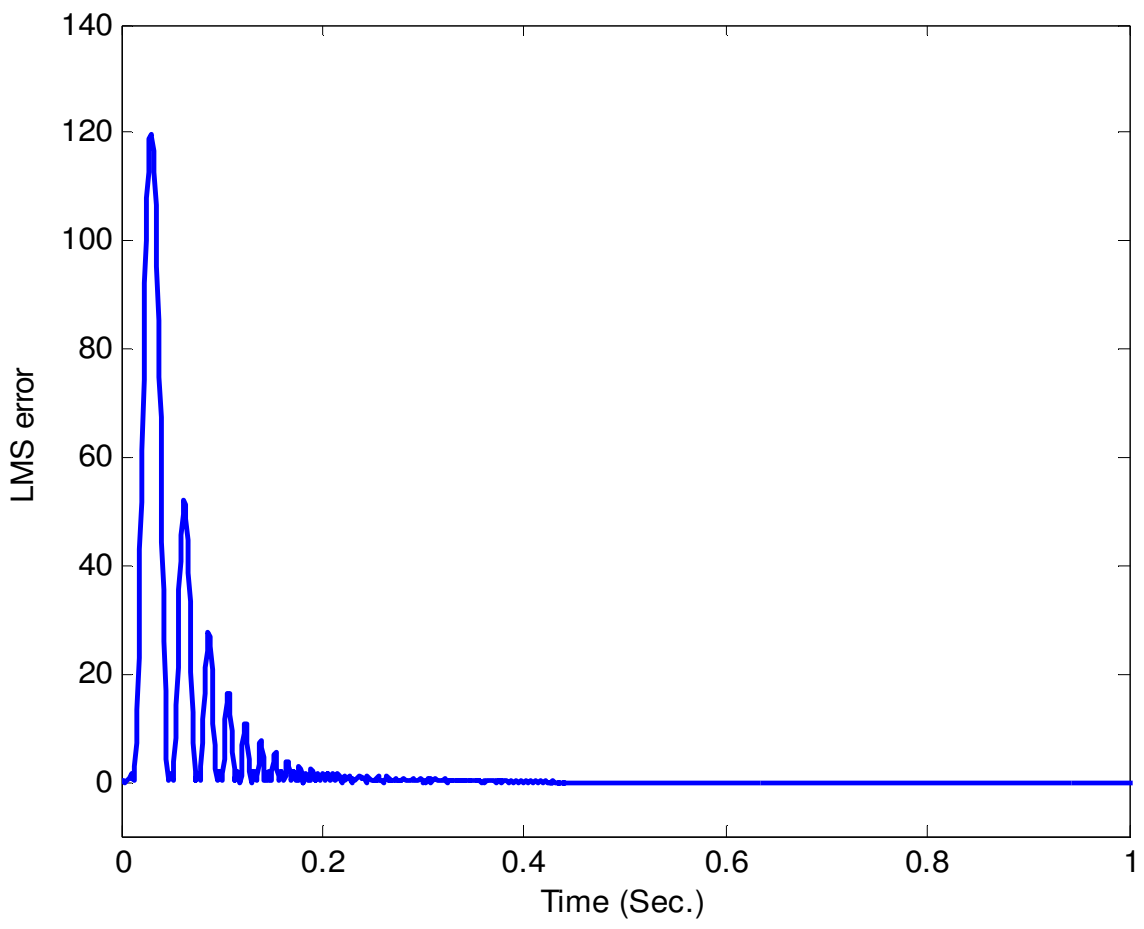

Figure 12. LMS error

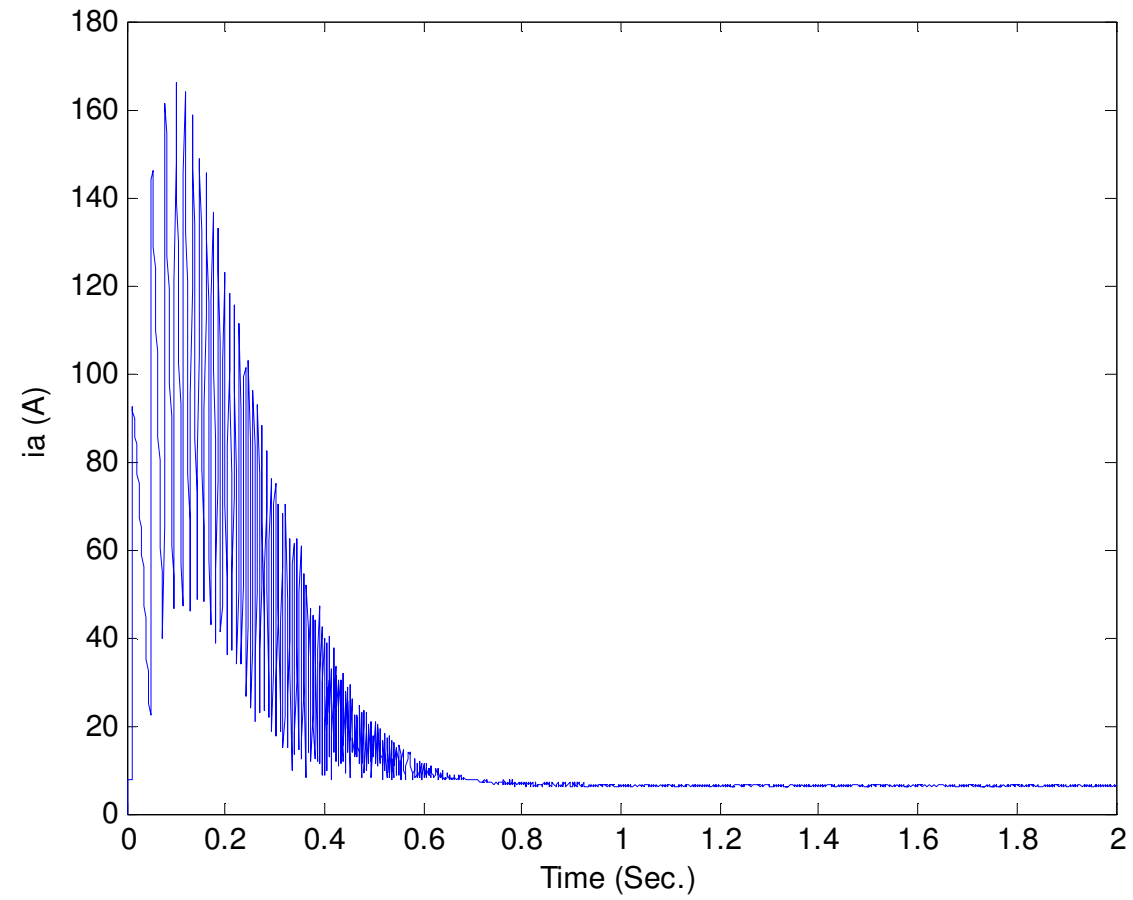

Figure 13. Armature current of the motor 
International Journal of Instrumentation and Control Systems (IJICS) Vol.2, No.4, October 2012

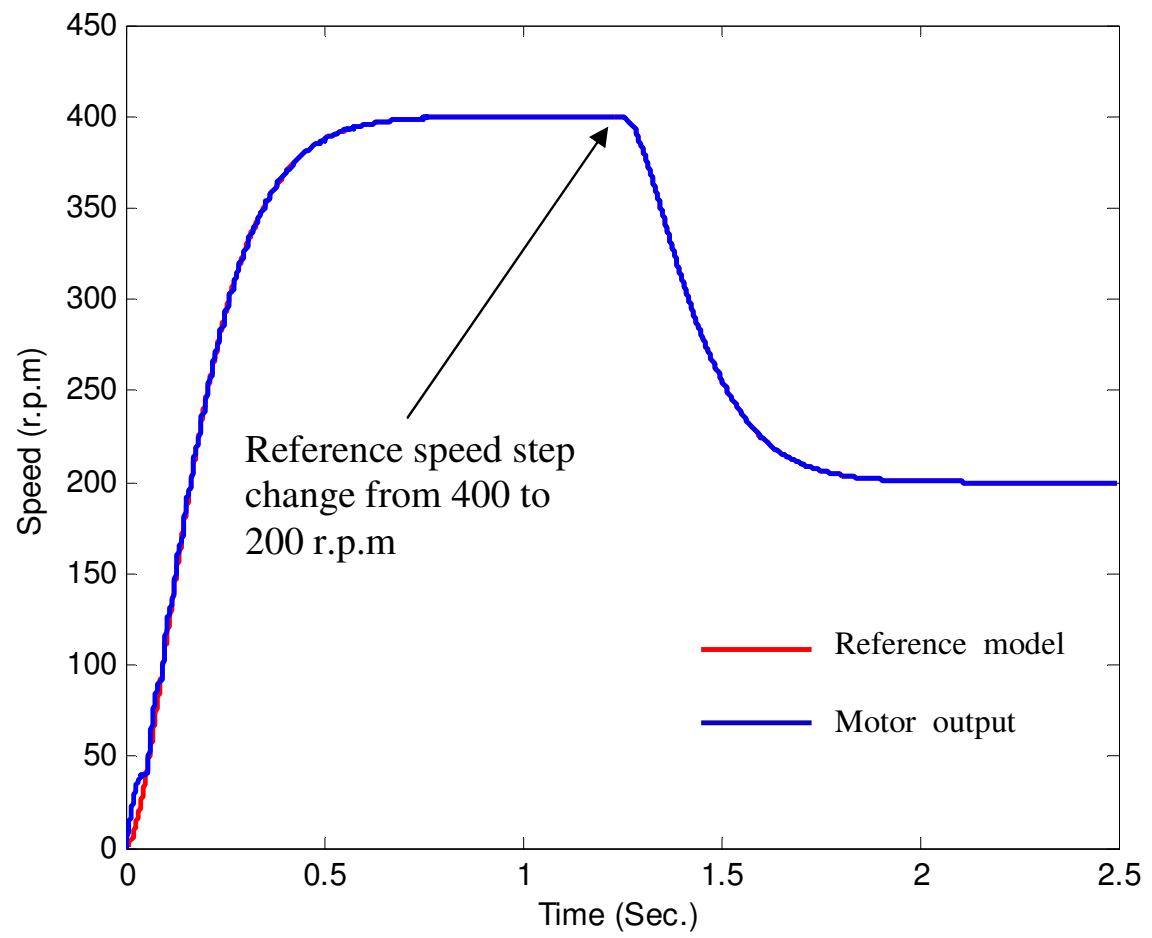

Figure 14. Rotor speed of the motor with step change in reference speed

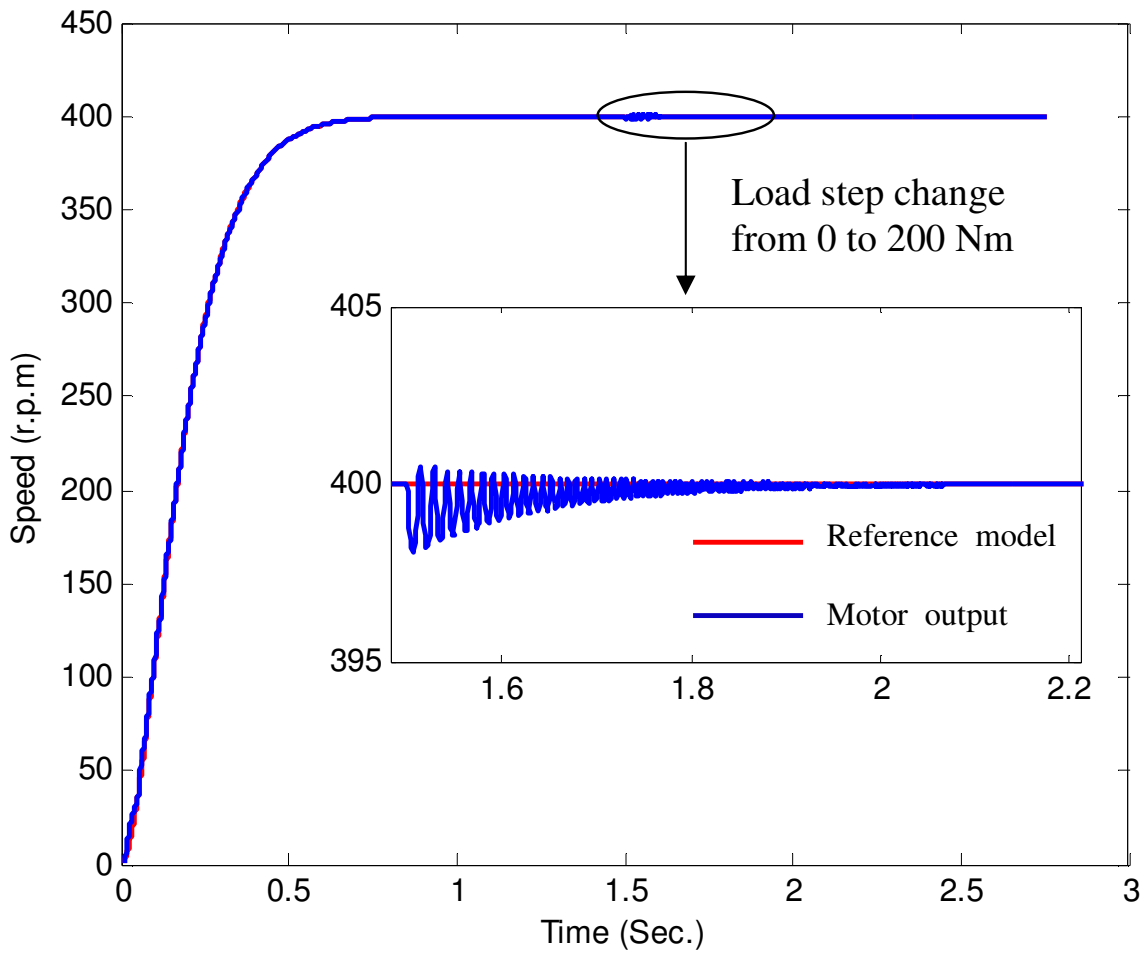

Figure 15. Rotor speed of the motor with step change in load torque 
International Journal of Instrumentation and Control Systems (IJICS) Vol.2, No.4, October 2012

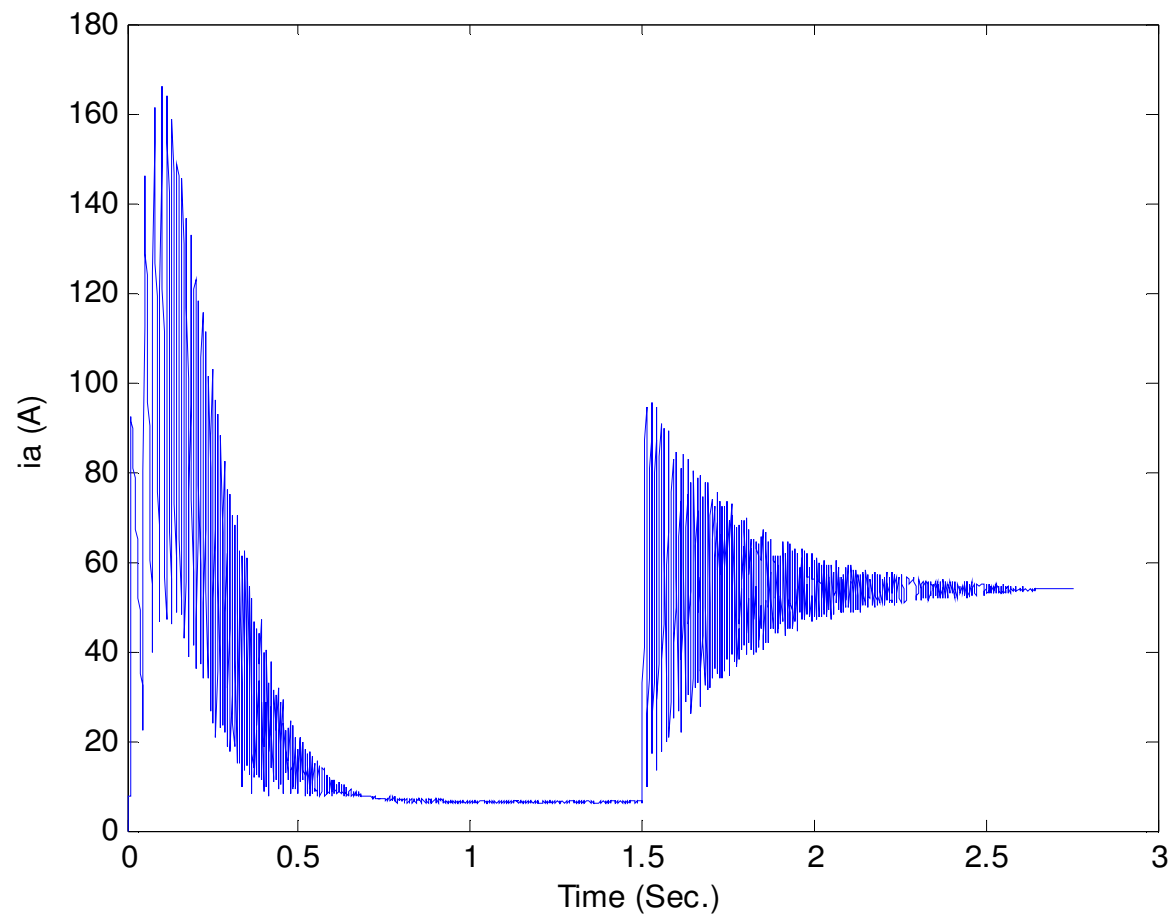

Figure 16. Armature current of the motor

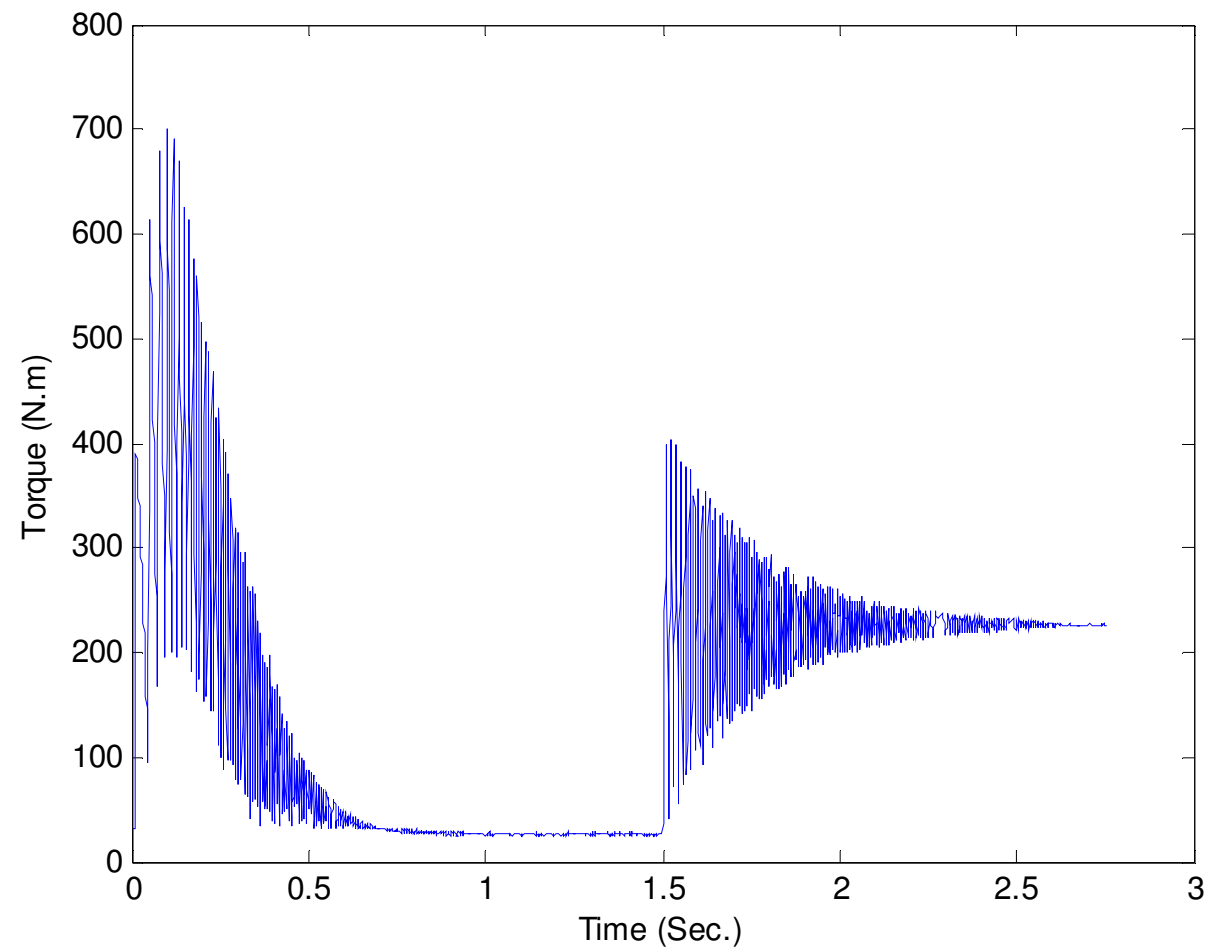

Figure 17. Internal torque of the motor with step change in load torque 
International Journal of Instrumentation and Control Systems (IJICS) Vol.2, No.4, October 2012

\section{CONCLUSIONS}

In this paper, Fuzzy Neural Model Reference Controller of separately excited DC motor has been presented. Fuzzy neural network has been used to control the speed of the motor. The error between the model reference output and motor speed output is used as trajectory function to adapting the primes part and the consequence part of the fuzzy-neural network so that the error goes toward zero. From simulation results, It is found that the proposed system is robust in that it eliminates the load disturbances considerably.

\section{REFERENCES}

[1] Singari.v.s.rPavankumar, Sande.krishnaveni, Y.B.Venugopal, Y.S.Kishore Babu, "A Neuro- Fuzzy Based Speed Control of Separately Excited DC Motor", IEEE Transactions on Computational Intelligence and Communication Networks, pp. 93-98, 2010.

[2] S. B. Dewan, Gordon R. Slemon, A. Straughen, "Power Semiconductor Drives", John Wiley \& Sons, 1984.

[3] Moleykutty George, Kartik Prasad Basu, Alan Tan Wee Chiat, "Model reference controlled separately excited DC motor", Springer, Neural Comput \& Application, vol. 19, Issue: 3, PP. 343$351,2010$.

[4] Adel Elkeshet, "New Developments Using ANFIS for DC Motors Speed Control", MSc.Thesis, Electrical and Computer Engineering, Dalhousie University, Canada, April, 2009.

[5] Bogdan M. Wilamowski, J. david Irwin, "Power electronIcs and motor drives", Taylor and Francis Group, LLC, USA, 2011.

[6] Jae-Sub Ko, Jung-Sik Choi, Dong-Hwa Chung, "Hybrid Artificial Intelligent Control for Speed Control of Induction motor", SICE-ICASE International Joint Conference, Oct. 18-21, in Bexco, Busan, Korea, PP. 678-683, 2006.

[7] Seong-Hwan Kim, Tae-Sik Park, Ji-Yoon Yoo, Gwi-Tae Park, "Speed-sensorless vector control of an induction motor using neural network speed estimation", IEEE Transactions on Industrial Electronics, Vol.48, Issue: 3, PP.609-614, June 2001.

[8] M. Brown, "Neuro Fuzzy Adaptive Modeling and control", Prentice Hill, International UK, 1994.

[9] T. Kara, I. Eker, "Nonlinear closed-loop direct identification of a DC motor with load for low speed two-directional operation", Springer, Electrical Engineering, vol. 86, Issue: 2, PP. 87-96, 2004.

[10] P.C. Sen, “Thyristor DC Derives”, John Wiley and Sons, NY, 1981.

[11] William Shepherd, Li Zhang, "Power Converter Circuit", Marcel Dekker, Inc, USA, 2004.

[12] R. Krishnan, "Electric Motor Drives, Modeling, Analysis, and Control", Prentice Hill, USA, 2001.

[13] Paul C. Krause, Oleg Wasynczuk, Scott D. Sudhoff, "Analysis of Electric Machinery and Drive Systwms", IEEE Press, USA, 2002

[14] Basma A. Omar, Amira Y. Haikal, Fayz F. Areed, "An Adaptive Neuro-Fuzzy Speed Controller for a Separately excited DC Motor", International Journal of Computer Applications, pp. 29-37, Vol. 39, No.9, February 2012.

[15] Salam Abdul Hady Abdul Kareem, "Fuzzy Neural And Fuzzy Neural Petri Nets Control For Robot Arm”, MSc.Thesis, Computers Engineering, Basrah University, September, 2010.

[16] Hasan Nassir Hasan AL-Salih, "Neurofuzzy Controller For The Induction Motor Speed UsingThe Slip Power Recovery Strategy", MSc.Thesis, Electrical Engineering, Basrah University, December, 2005.

[17] M. S. Mostafa, M. A. El-Bardini, S. M. Sharaf, M. M. Sharaf, "Fuzzy neural networks for identification and control of DC drive systems",IEEE International Conference on Control Applications, pp. 598-603, Vol.1, 2004.

[18] Ahmed Thamer Radhi, "Power System Protection Using Fuzzy Neural Petri Net", Ph.D. Thesis, Electrical Engineering, Basrah University, February, 2012.

[19] Khearia A. Mohamad, "Fuzzy Neural Controller For Multi-Machine Induction Motor Drives", Ph.D. Thesis, Electrical Engineering, Basrah University, February, 2009. 